\title{
Newfoundland Neogene sediment drifts: transition from the Paleogene greenhouse to the modern icehouse
}

\author{
O. Friedrich ${ }^{1}$, R. D. Norris ${ }^{2}$, P. A. Wilson ${ }^{3}$, B. N. Opdyke ${ }^{4}$, and workshop participants \\ ${ }^{1}$ Institute of Earth Sciences, Universität Heidelberg, Im Neuenheimer Feld 234-236, \\ 69120 Heidelberg, Germany \\ ${ }^{2}$ Scripps Institution of Oceanography, University of California San Diego, 9500 Gilman Drive, \\ La Jolla, CA 92093-0244, USA \\ ${ }^{3}$ National Oceanography Centre Southampton, University of Southampton, Waterfront Campus, \\ Southampton, SO14 3ZH, UK \\ ${ }^{4}$ Research School of Earth Sciences, College of Physical and Mathematical Sciences, The Australian National \\ University, Building 142 Mills Rd, Canberra, ACT 0200, Australia
}

Correspondence to: O. Friedrich (oliver.friedrich@geow.uni-heidelberg.de)

Received: 28 February 2015 - Revised: 27 April 2015 - Accepted: 5 May 2015 - Published: 29 May 2015

\begin{abstract}
This workshop brought together specialists from various fields to develop a drilling proposal to fill the "Oligo-Miocene Gap" that exists in our understanding of the functions of Earth's systems. We propose to establish the first continuous high-deposition record of the Oligo-Miocene through new International Ocean Discovery Program (IODP) drilling in the North Atlantic to allow the development of a continuous Neogene cyclostratigraphy and to enhance our knowledge of Oligo-Miocene ocean-ice-climate dynamics. The workshop was held in Heidelberg from 15 to 17 September 2014 funded by ESF (EARTHTIME EU), NSF, and the ECORD MagellanPlus Workshop Series Program. A total of 24 participants from six different countries (Australia, France, Germany, the Netherlands, United Kingdom, and United States) attended the workshop, including several early career stage researchers. We discussed certain aspects of Cenozoic paleoceanography and paleoclimate and how the gaps in the Oligo-Miocene could be filled using scientific drilling. The ultimate goal of the workshop (to submit a pre-proposal to IODP) was achieved (IODP Proposal 874-pre was submitted 1 October 2014). Our workshop consisted of overview presentations followed by self-selected breakout groups that discussed different topics and produced text and figures for the proposal. Here, we give a short overview of the major topics discussed during the workshop and the scientific goals presented in the resulting IODP pre-proposal.
\end{abstract}

\section{Scientific rational of the workshop}

The Oligo-Miocene time interval $(\sim 34$ to $\sim 5 \mathrm{Ma}$ ) represents a critical phase of Earth's history after development of Antarctic ice sheets but before large-scale glaciation in the Northern Hemisphere (e.g., Zachos et al., 2001, 2008; Pälike et al., 2006). However, well-resolved marine records spanning this time interval from the high northern latitudes are scarce and incomplete, restricting our view of the early transition into glacial climates and ecosystems in the Northern Hemisphere. A key region is the mid-to-high-latitude North Atlantic Ocean, which represents a global "end mem- ber" of deep-water overturning and cryosphere evolution, and a sensitive recorder of both terrestrial and marine highlatitude ecosystems. Of interest are the interaction among global temperature, atmospheric $p \mathrm{CO}_{2}$, deep-water circulation, ice-sheet volume, and ecosystems that all experience state changes in the Oligocene-Miocene interval resulting in the establishment of near-modern Earth systems.

IODP Proposal 874-pre was submitted as a direct outcome of the workshop. In it we propose to drill high-deposition records of the Oligocene-Miocene interval from the same region of deep-sea sediment drifts that was sampled during the highly successful, early Paleogene-focused Expedi- 


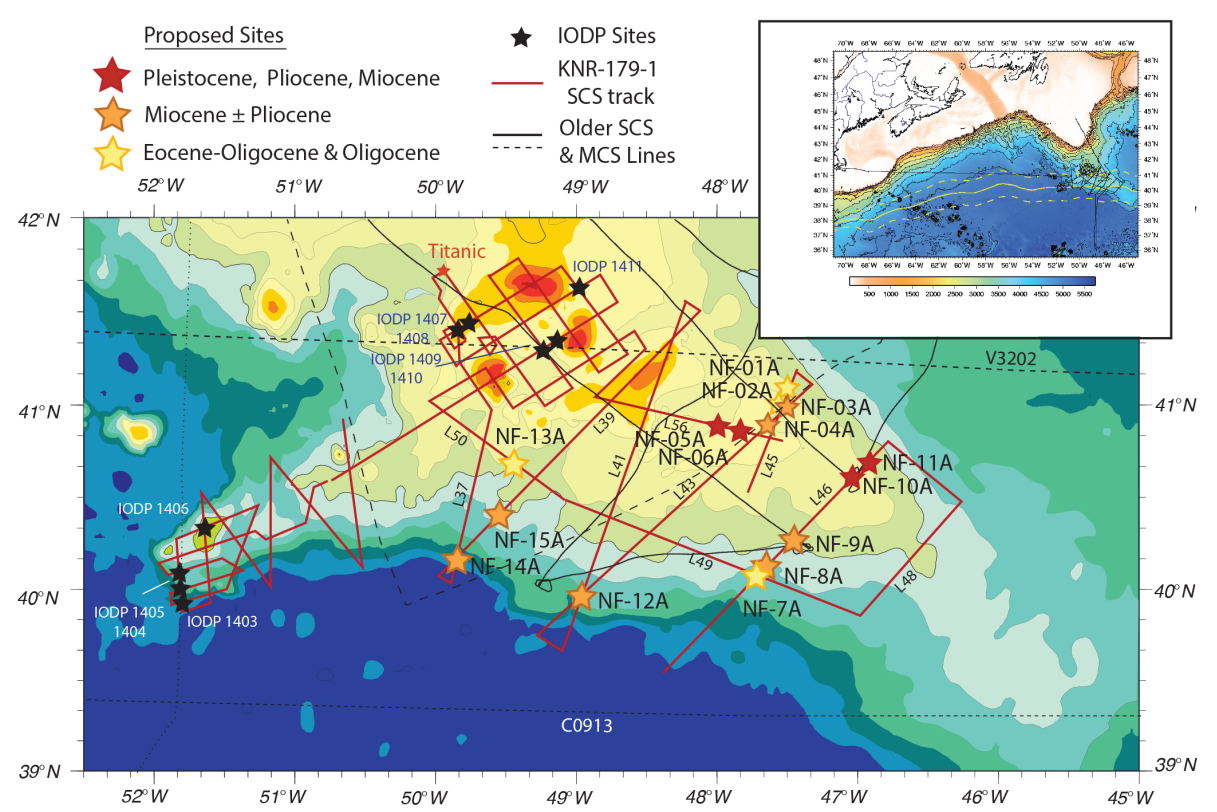

Figure 1. Track map for Newfoundland ridges showing existing SCS and MCS lines and proposed drill sites. Stars of different colors reflect the predominant age for the drilling targets at each site. Black stars are previous Eocene-focused sites drilled during IODP Expedition 342 (Norris et al., 2014).

tion 342 (Fig. 1). That leg targeted sediment drifts of Eocene age on the Newfoundland ridges that proved to have excellent microfossil preservation, magnetostratigraphy, and cyclostratigraphy (Norris et al., 2014). Drilling and the highquality seismic grid over the Newfoundland ridges reveal the existence of highly expanded Oligocene, Miocene, and Pliocene drift deposits in the region (for an example see Fig. 2). The drifts provide the depth range and temporal record to reconstruct the latest Paleogene-Neogene companion record to Expedition 342's early Paleogene climate history, taking advantage of high sedimentation rates that allow us to obtain very detailed records of Oligocene to Miocene climate events and paleoceanography. New records from the Oligocene and early Miocene can also be linked to Expedition 342's deep-water sites (Norris et al., 2014) to fully reconstruct the North Atlantic carbonate compensation depth.

\section{Discussions during the workshop and direct outcome}

The workshop was held from 15 to 17 September 2014 at the Internationales Wissenschaftsforum Heidelberg, Germany. It was the result of various discussions between the convenors and participants in IODP Expedition 342 between 2012 and 2014 that finally led to the organization of the workshop. Having a large amount of information (seismics and stratigraphy) from the foregoing Expedition 342 in the same drilling area, the scientific questions to be answered and potential drill sites could be effectively discussed during the 3-day-long workshop.

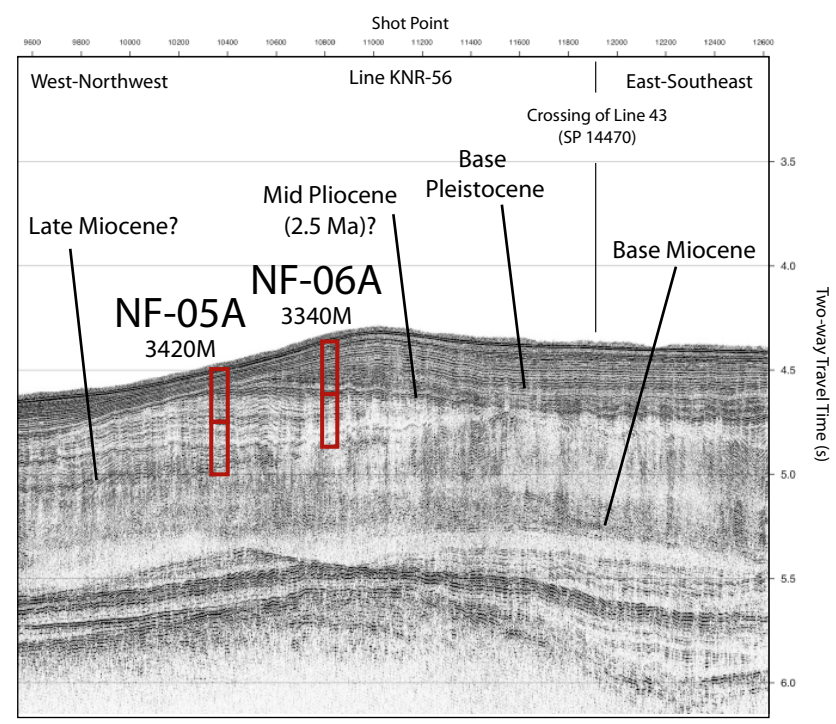

Figure 2. Example of seismic line showing the Miocene drilling target as it appears in seismics at the SE Newfoundland ridges. Two proposed drill sites (NF-05A and NF-06A) are shown for visualization. Red bars indicate a penetration depth of $500 \mathrm{~m}$ below sea floor.

The first day was devoted to overview presentations of major scientific themes and questions to set the ground for the following group discussion that took place on the same day. During the discussion, the potential to propose a new IODP expedition to Newfoundland was evaluated. Furthermore, potential links to the existing IODP Proposal 851- 
pre (Cenozoic Evolution of the North Atlantic - the Western Atlantic Latitudinal Transect) were discussed because 851 has complementary aims compared to the planned Newfoundland pre-proposal. While the Newfoundland proposal focuses on high-resolution drift sediments from the OligoMiocene, proposal 851-pre targets a longer time interval of the Cenozoic but with lower sedimentation rates.

The workshop showed that there is a major, persistent gap in recovery of high-deposition records of OligoceneMiocene age in the North Atlantic. This gap persists despite the importance of this area and time interval for understanding the evolution of the cryosphere, Northern Hemisphere ecosystem structure, and the history of ocean productivity and chemical balances. Recent drilling in this time interval has focused on the Pacific where new, very highly resolved records with good chronology have been produced (e.g., Holbourn et al., 2013; Tian et al., 2013). A key task is therefore to produce comparable records from the sites of deep ocean overturning in the Atlantic for understanding the relative contributions of regional and global signals preserved in the $\mathrm{Pa}$ cific records.

Our new pre-proposal focuses on Oligocene-Miocene objectives, particularly the Middle Miocene Climatic Optimum (15-17 Ma). This drilling strategy acknowledges the importance of focusing on extreme climate dynamics (such as the abrupt warming and carbon-cycle dynamics of the middle Miocene).

The participants in the workshop also recognized the value of obtaining both continuous but low-temporal-resolution records from pelagic sites (covered in 851-pre) and highresolution drift records. The high-resolution record is the target of proposal 874-pre, which was submitted 1 October 2014 as a direct outcome of this workshop. There was also interest in locating one or more sites off West Africa (near Morocco) to obtain a Oligocene-Miocene sediment record with a precession-dominated aridity record, like existing Pliocene records in the Mediterranean. Mediterranean records have proven very useful in adjusting the details of the Pliocene timescale since the aridity record does not require assumptions about orbital tuning of the high-latitude glacial cycle. However, no specific West African drilling target was identified during the meeting. Nonetheless, participants left the meeting agreeing on the importance of drilling off West Africa to extend the orbital timescale back into the early Neogene and update the widely used LR04 stack (Lisiecki and Raymo, 2005) of oxygen isotope records used in the Pliocene timescale.

The following 2 days of the workshop were dedicated to the development of scientific questions and text writing as well as figure drafting for the planned pre-proposal. During this phase of the workshop, analysis of existing seismic data for the SE Newfoundland Ridge (available from previous IODP Expedition 342) was used to identify 15 primary and alternate drill sites that could cover the entire OligocenePliocene sequence with high deposition rate sections. These prospective drill sites also span a $\sim 1800 \mathrm{~m}$ depth transect, including abyssal sites at up to $5 \mathrm{~km}$ water depth. All but three of these sites would be drilled entirely with advanced piston coring (APC) to depths of $\sim 250 \mathrm{~m}$.

Immediately following the workshop, on 18 to 19 September 2014, the convenors continued to work on the proposal structure, site forms, cover sheet, and editing text in order to submit an IODP pre-proposal. As a direct outcome of the workshop, IODP Proposal 874-pre was submitted on 1 October 2014 to drill Neogene Newfoundland drift sediments.

\section{Future impact of the workshop}

Regarding the initial goals, the workshop was highly successful since the outcome was a submitted pre-proposal to IODP (874-pre) and a re-evaluation and revision of an existing preproposal (851-pre). For both pre-proposals, text and figures were produced by the participants that can be used by the proponents to submit one or two full proposals to IODP. In the case of 874-pre, the development of a full proposal was recommended by the Science Evaluation Panel based on the evaluation of the proposal in January 2015.

In the event that either of these two expeditions are scheduled by IODP, the workshop will have a great impact on our knowledge of North Atlantic paleoceanography and paleoclimate and will serve as resource for many scientific proposals from the international scientific community. Scientific ocean drilling in the Atlantic Ocean based on these two proposals will massively increase our understanding of the feedbacks and function of Earth's systems through recovery of archives with millennial-scale temporal resolution as well as long-term records. In combination with previous drilling, the planned continuous high-deposition record of the Cenozoic could be used to establish a sophisticated orbital age model for most of the Cenozoic to investigate the spatial and temporal dimension of single events as well as long-term evolution of the Earth's system.

\section{Participants in the workshop}

The participants in the workshop (Fig. 3) are in alphabetical order (names in italic: ECRs):

Markus Badger (University of Bristol), Ian Bailey (University of Exeter), Helen Beddow-Twigg (University of Utrecht), Steven Bohaty (NOCS), Clara Bolton (CEREGE), André Bornemann (BGR), Anja Crocker (NOCS), Oliver Friedrich (University of Heidelberg), Jens Grützner (AWI), Timothy Herbert (Brown University), Ann Holbourn (University of Kiel), Pincelli Hull (Yale University), Diederick Liebrand (NOCS), Peter Lippert (University of Utah), Lucas Lourens (University of Utrecht), Mitch Lyle (Oregon State University), Richard Norris (Scripps Institution of Oceanography), Bradley Opdyke (ANU), Jörg Pross (University 


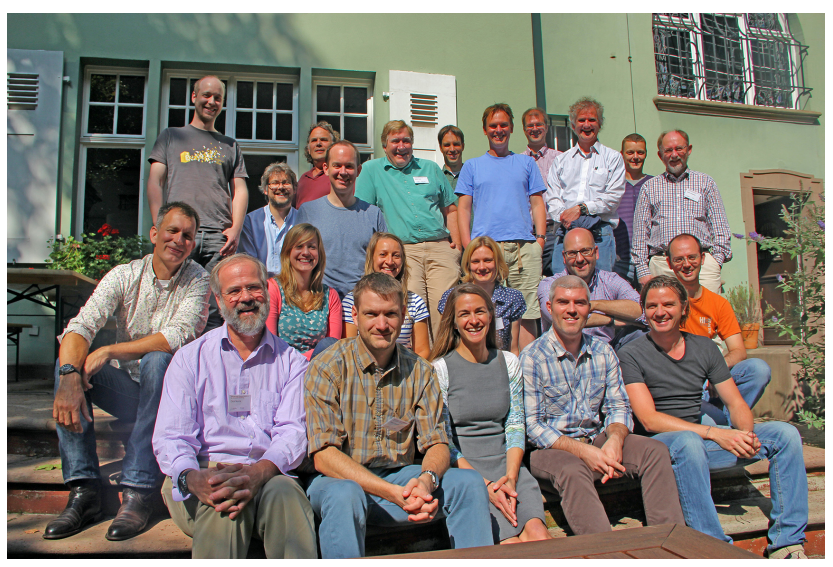

Figure 3. Group photo of workshop participants in front of the IWH venue. Photo: Lucas Lourens.

of Heidelberg), Yair Rosenthal (Rutgers State University), Phil Sexton (The Open University), Michael Stärz (AWI), Thomas Westerhold (MARUM), and Paul Wilson (NOCS).

Acknowledgements. We thank ECORD-ICDP MagellanPlus Workshop Series Program, NSF and ESF (Earthwork EU) for financial support for this workshop and the Internationales Wissenschaftsforum Heidelberg (Ruprecht-Karls-Universität Heidelberg) for hosting the event. All participants in the workshop and proponents of the pre-proposal are thanked for fruitful and successful discussions. Two anonymous reviewers and the editor are thanked for helpful comments and handling the manuscript.

Edited by: G. Camoin

Reviewed by: two anonymous referees

\section{References}

Holbourn, A. E., Kuhnt, W., Clemens, S. C., Prell, W., and Andersen, N.: Middle to late Miocene stepwise climate cooling: Evidence from a high-resolution deep-water isotope curve spanning 8 million years, Paleoceanography, 28, 688-699, doi:10.1002/2013PA002538, 2013.

Lisiecki, L. E. and Raymo, M. E.: A Pliocene-Pleistocene stack of 57 globally distributed benthic delta-18O records, Paleoceanography, 20, PA1003, doi:10.1029/2004PA001071, 2005.

Norris, R. D., Wilson, P. A, Blum, P., and the Expedition 342 Scientists: Proc. IODP, 342: College Station, TX (Integrated Ocean Drilling Program), doi:10.2204/iodp.proc.342.2014, 2014.

Pälike, H., Norris, R. D., Herrle, J. O., Wilson, P. A., Coxall, H. K., Lear, C. H., Shackleton, N. J., Tripati, A. K., and Wade, B. S.: The heartbeat of the Oligocene climate system, Science, 314, 1894-1898, 2006.

Tian, J., Yang, M., Lyle, M. W., Wilkens, R., and Shackford, J. K.: Obliquity and long eccentricity pacing of the Middle Miocene climate transition, Geochem. Geophy. Geosy., 14, 1740-1755, 2013.

Zachos, J. C., Dickens, G. R., and Zeebe, R. E.: An early Cenozoic perspective on greenhouse warming and carbon-cycle dynamics, Nature, 451, 279-283, 2008.

Zachos, J. C., Pagani, M., Sloan, L., Thomas, E., and Billups, K.: Trends, rhythms, and aberrations in global climate 65 Ma to present, Science, 292, 686-693, 2001. 